Among moulds, certain species of Mucor exist as several races the individuals of each of which reproduce themselves asexually, but do not conjugate with one another. When, however, individuals of different races meet, they conjugate and produce zygospores. It may be supposed that one race is of such a type as MMff, another of the $m m \mathrm{FF}$ type. In this case verification of the hypothesis is possible.

The absence of sexual reproduction in various groups of fungi is to be explained on the present hypothesis as due to the extinction (or effective separation) of all zygotes except those of one type, e.g. the Mf or the $m \mathrm{~F}$ types.

In homosporous ferns, the spores, produced after the reduction division, give rise each to a prothallus which bears male and female organs. If it be allowed that the reduction division is of fundamental significance with respect to the segregation of characters, it would appear to follow that current Mendelian theories of sex-heredity fail to account for the fact that a spore produced as a consequence of the reduction division may yet carry "male" and "female" factors.

The phenomena may be interpreted simply in terms of the new hypothesis. The fern plant is MMFF; the spore, and hence the prothallus, carries MF. Therefore male and female organs may be produced by the prothallus. The gametes formed and matured in the female organs are "female," those formed and matured in the male organs are "male."

In the heterosporous ferns the spores are of two kinds, macrospores, giving rise to "female" prothalli, and microspores, which give rise to " male" prothalli. In terms of our hypothesis the sporophyte (zygote) is $\mathrm{MmFf}$, the megaspore $m \mathrm{~F}$, and the microspore $\mathrm{M} f$

Further, the high rate of mortality which accompanies spore-formation receives on this hypothesis an intelligible explanation. It is due to the inevitable reappearance of combinations of sex-characters which the heterosporous fern has ceased to tolerate.

In the light of the present hypothesis, homosporous ferns are homosporous because they are homozygous, and heterosporous ferns are heterosporous because they are heterozygous for the sex characters $M$ and $F$.

The significant question arises, How far is the present limitation of characters presented by any great group of organisms determined by the fact that in this group the task of reproduction has come to be committed to some particular type or types of gametes?

The hypothesis would appear to throw light on large numbers of known facts, on prepotency, partial sterilitysuch, for example, as occurs in heterostylism-the apparently excessive production of pollen and ovules, and so forth.

Not only is it not repugnant to a reasonable explanation of many facts, but also the hypothesis does not seem to be inherently improbable. In that it is based on the presence and absence theory, it receives the sanction of Mendelism. It tempts the imagination to trace the origin of sexuality from the " self-contained "organisms of the MF type. Evolution in such types took, in some individuals, the form of a dropping out of the $M$, in others, of a dropping out of the F, factor. Such incomplete forms as $\mathrm{Mf}$ and $\mathrm{F} m$ discovered in fusion the means of restoring their constitutions; but out of this fusion possibilities for novel constitutions arose, for the $\mathrm{MmFf}$ type of zygote was now in being. In reproducing by segregation the original MF type of gamete, the zygote was constrained to produce likewise the other possible combinations of $\mathrm{M} m$ and $\mathrm{Ff}$. Fusions between the several types resulted in different forms of zygote; evolution had its chance.

Among other types, the pure recessive, $m m f f$, arose, and, with its advent, sterility, and, it may be, death, came on the scene as the sinister shadow of "sexual "reproduction.

It only remains to add to this note that-in case the hypothesis it proposes prove of value-though the responsibility for the hypothesis rests with the writer, the stimulus to which it owes its inception originated, in the first place, from a study of Bateson's work on heredity, and in the second place from discussions on the problems of heredity between the writer and his colleagues, Miss Rayner, Mr. Jones, and Miss Pellew, of the botanical laboratory, to whom certain of the foregoing illustrations are due.

University College, Reading. NO. 2 I 04 , VOL. 82]

\section{Geology and the Earth's Axis of Rotation.}

From time to time the pages of NATURE contain references to the theory which would explain the occurrence of Ice ages by a hypothetical shifting of the earth's axis of rotation. On the face of it, the theory in question appears to be capable of explaining a good deal more than this.

In the first place, if the axis of rotation were to be shifted, it seems clear that the relations between the carth's hydrosphere (or hydrospheroid) and the lithosphere must undergo change. In the regions towards which the pole is approaching land will tend to emerge from the sea, and vice versa. If the effects of this supposition be traced out in detail, they will be found to furnish an explanation of such phenomena as raised beaches, submerged river valleys, varying continental connections \&c., without postulating violent alterations in the lithosphere itself. Speaking merely qualitatively, the hypothesis seems to fit the facts pretty closely, e.g. (a) the height of raised beaches tends to increase as one approaches the polar regions, as it ought; (b) a marine transgression is associated with a warm climate.

In the second place, a shifting of the polar axis will not be without effect on the lithosphere itself, although such effect would not, presumably, under present conditions, at all resemble the effect on the hydrosphere already alluded to. Even in a rough qualitative way this effect is not easily traced out, but it seems tolerably clear that it will account for those processes of folding, \&c., whereby mountain chains are built up, and also for extensive local subsidences such as are believed to have occurred in geological time. These, and doubtless other phenomena, the hypothesis explains without having recourse to the supposition that the earth has been undergoing contraction through loss of heat.

I am not aware of the existence of any publications dealing with the matters referred to, but as the subject appears to be not without interest, perhaps some of your other readers will be able to refer me to papers, \&c. treating of the subiect with which they may be acquainted. I should be particularly glad to be referred to researches in which the subject is treated quantitatively.

Holyrood House, Bo'ness, Linlithgowshire, N.B.,

February 4 .

\section{Secondary Cells in Tropical Climates.}

ALL who have used batteries of small secondary cells in the tropics will have experienced the difficulty of keeping their cells in efficient working order, and especially in preserving the junction of separate cells from rapid corrosion. The difficulty, appreciable in Europe, becomes very serious in a climate where the laboratory temperature lies between $30^{\circ}$ and $40^{\circ} \mathrm{C}$, and for this reason-it is probable that practically all accumulators sent to tropical countries by European manufacturers are filled by their recipients with dilute sulphuric acid of a density ( 1,190$)$ which corresponds to a 20 per cent. mixture in north Europe at $15^{\circ}$ to $20^{\circ}$ C., but at a temperature of $30^{\circ}$ to $35^{\circ} \mathrm{C}$. indicates a mixture which is far too rich in acid for the health of the cells. Some simple experiments recently carried out in this laboratory exhibit quite clearly how large a deviation from the standard 20 per cent. mixture is caused by filling cells at $30^{\circ}$ with dilute acid of density I, I9O. It is found that a density of $\mathrm{I}, \mathrm{I} 90$ at $30^{\circ}$ corresponds to a composition of 23 per cent., whereas the value of the composition accepted as giving the best results with cells of this type is 20 per cent. The difference is as much as half the total change in composition due to chemical action during the process of charging the cell.

The conclusion reached from an examination of the density-temperature curves for dilute sulphuric acid points to the advisability of filling all secondary cells in localities where the average temperature is $30^{\circ}$ or more with acid solution of density about r.17o. Densities as low even as I, I 50 have been found satisfactory for small secondary cells in the hot weather in Calcutta.

In the case of large plants in power stations, the matter may be still more important, as a cell containing too strong 